\title{
Trampas do traje*
}

Mariza Corrêa**

\section{Resumo}

O fato de que o melhor da poesia latino-americana no século dezessete tivesse se encarnado numa autora, numa época em que as mulheres eram em geral iletradas, já é, por si só, algo que merece reflexão. $\mathrm{O}$ fato de que, ao contrário do que dizem vários dos comentaristas de sua obra, ela não se masculinizou, mas que, sim, seus interlocutores foram obrigados a se feminizar para se opor a ela, também parece interessante. $\mathrm{O}$ artigo faz uma breve incursão pelo mundo de Sor Juana, na esperança de que ela venha a ser mais conhecida dos leitores brasileiros.

Palavras-chave: Juana Inês de la Cruz, Travestismos, Poesia Latino-Americana, México.

\footnotetext{
* Recebido para publicação em dezembro de 2003, aceito em março de 2004.

** Pesquisadora do Núcleo de Estudos de Gênero - Pagu e professora convidada do Departamento de Antropologia, Instituto de Filosofia e Ciências Humanas, ambos da Unicamp.mariza@unicamp.br
}

cadernos pagu (22) 2004: pp.185-200. 
Trampas do traje

\title{
Garments Gambits
}

\begin{abstract}
That a woman was considered to be the best poet in Latin America in the 17th century is in itself worth of consideration since most women there, and around the world, were then illiterate. That she was not mannish, as many have hinted, but instead, that her opponents were obliged to feminize themselves to face her seems interesting. This article tries to call attention to Sor Juana's life and works.
\end{abstract}

Key Words: Juana Inés de la Cruz, Travestism, Latin American poetry, Mexico. 
Mariza Corrêa

Si Aristoteles hubiera guisado, mucho más hubiera escrito. Sor Juana Inés de la Cruz

\section{Breve recapitulação da vida de Juana}

Por ser pouco conhecida por estas plagas, a história de Juana de Asbaje merece uma rápida recapitulação. Nascida num pequeno povoado mexicano, em 1651, segundo a história oficial, ou em 1648, de acordo com a documentação examinada por Octavio Paz ${ }^{1}$, a trajetória dessa menina bastarda assemelha-se em muitos aspectos à de várias outras meninas de seu século. Sem pai nem dote, viveu dos oito aos dezesseis anos com parentes abastados na cidade do México, foi depois colocada por eles como dama na corte do vice-rei do território que era então a Nova Espanha, obteve uma dotação de um fidalgo católico que lhe permitiu tornar-se freira, tendo morrido, aos 44 ou 47 anos, no mesmo convento da Ordem de São Jerônimo, no qual professara aos 18 ou 21 anos, conforme a data que se aceite como de seu nascimento.

Aqui cessam as semelhanças com as outras meninas de sua época e condição: tendo aprendido a ler muito cedo, na biblioteca de seu avô materno, Juana nunca mais abandonou os livros - seu biógrafo faz uma excursão pelo impressionante conhecimento de época dominado por ela, analisando as referências em suas obras poéticas - e seus retratos sempre a mostram vestida de monja tendo ao fundo sua biblioteca. Apenas duas coletâneas de seus trabalhos foram publicadas durante sua vida, em 1689 e 1692 , ambas na Espanha e ambas encomendadas pela esposa do vicerei que voltara para seu país, e da qual se tornara amiga, a Condessa de Paredes - Maria Luísa Manrique de Lara. Seus manuscritos e suas cartas se perderam, o que torna incerta a

1 Paz, Octavio. Sor Juana Inês de la Cruz o las trampas de la fe. México, Fondo de Cultura Económica, 1982. 
Trampas do traje

atribuição de datas à sua produção literária - boa parte dela, segundo Octavio Paz, eram versos ou peças teatrais de ocasião: a chegada de um novo vice-rei, a morte de outro, um batismo, uma data comemorativa. Perderam-se também em conjeturas suas possíveis contribuições à música e à pintura: há quem atribua a ela a autoria de um dos seus retratos.

Octavio Paz comenta sua poesia com grande admiração e aponta para o fato de que,

por mais antiga e ilustre que seja a tradição da literatura erótica e até libertina escrita por religiosos [..] não há na história de nossas letras outro exemplo de uma monja que tenha sido, com o aplauso de todos, autora de poemas eróticos e também de sátiras sexuais que poderiam ter sido assinadas por um discípulo de Quevedo.

E conclui que sua impunidade devia-se à proteção do palácio e à própria ambigüidade de sua situação:

ao mesmo tempo que escrevia vilancicos [canções de natal e outras festas] para a catedral e loas para o palácio, compunha sonetos e liras de amor. Uma atividade compensava a outra. ${ }^{2}$

Tal impunidade não duraria para sempre. Octavio Paz pinta o cenário dos últimos anos de Sor Juana: em 1691, chuvas e inundações, seguidas de perda das colheitas, deram origem a motins e protestos na cidade do México, que culminaram com o incêndio do palácio do novo vice-rei - a esta altura asilado num monastério - e a execução de vários amotinados, a maior parte indígenas. Procissões e auto-flagelações públicas, éditos do arcebispo contra os especuladores, que armazenavam grãos, aliados à tibieza do vice-rei, tornaram a Igreja o "sustentáculo das instituições" em meio a um clima geral de "castigo de Deus" pelas

2 ID., IB., p.368. 


\section{Mariza Corrêa}

catástrofes naturais e sociais. Sor Juana perdia seus aliados no paço - e não os tinha no palácio do arcebispo. ${ }^{3}$ Assim, diz Paz, quando o segundo tomo das obras de Sor Juana chegou ao México, foi visto como um desafio às leis naturais e manifestação de rebeldia de uma religiosa. Solitária, Sor Juana mandou chamar seu antigo confessor, com quem havia rompido, e assinou uma confissão por seus pecados: "há tantos anos que vivo na religião, sem religião, senão pior do que poderia viver um pagão", diz um trecho do texto. ${ }^{4}$ Passou a fazer uso de cilícios e, finalmente, em 1694, entregou seus livros, instrumentos musicais e instrumentos científicos ao arcebispo para que os vendesse e distribuísse o

3 Paz pinta o arcebispo como um misógino e também inimigo das letras. Que o perigo rondava Sor Juana é indicado pelo número de vezes em que ela menciona não ter ofendido o Santo Ofício, na famosa Respuesta a sor Filotea (1691), texto no qual sua altivez também transparece em todas as linhas. Na carta ela responde a acusações que lhe teriam sido feitas por ter publicado uma crítica a um sermão do Padre Antonio Vieira. Diz ela, a certa altura: "Se é, como diz o censor, herética, porque não a denuncia? Com isso, ele ficará vingado e eu contente, pois aprecio, como devo, mais o nome de católica e de filha obediente de minha Santa Madre Igreja do que todos os aplausos por douta. Se está bárbara, que nisso acerta, ria-se, ainda que seja, como se diz, com o riso dos coelhos; que eu não lhe digo que me aplauda, pois, como fui livre para dissentir de Vieira, o será qualquer um para dissentir de minha opinião." IMBERT, Enrique Anderson e FlORIT, Eugenio. Literatura hispano-americana. Antologia e introducción histórica. N.Y., Holt, Rinehart and Winston, 1960, p.145.

4 Octavio Paz desdenha da interpretação dos biógrafos religiosos de Sor Juana de que ela tenha abdicado de suas atividades literárias, conforme reza o título da profissão de fé de 1694: "Declaração que, assinada com seu sangue, fez de sua fé e amor a Deus a madre Juana Inês de la Cruz, quando abandonou os estudos humanos para prosseguir, livre desta inclinação, no caminho da perfeição." O poeta argumenta que ninguém viu o documento original, impresso pela primeira vez num dos livros póstumos de Sor Juana; que o título foi, provavelmente, atribuído pela mesma pessoa que nomeara outras peças literárias desse livro, e que não há, no texto, qualquer menção daquele abandono - tratando-se segundo ele de uma peça que seguia as convenções religiosas da época. E acrescenta que, quando morreu, Sor Juana deixou um poema inacabado no qual retomava os mesmos temas tão caros a outros textos seus: seu único mérito havia sido estudar, sendo mulher, e estudar sem professores. PAZ, O. Sor Juana Inês de la Cruz... Op. cit., p.592. 
Trampas do traje

obtido entre os pobres. Morreu um ano depois, como tantas outras religiosas do Convento de São Jerônimo, quando ele foi atingido por uma epidemia desconhecida.

\section{Artes de Sor Juana}

Ler e escrever não eram as únicas ocupações de Sor Juana no convento - em várias linhas e entrelinhas ela conta como as atividades cotidianas em São Jerônimo interferiam com sua rotina intelectual. ${ }^{5}$ Cozinhar era uma dessas atividades e Sor Juana usa sua experiência na cozinha para fazer ironias a respeito da posição das mulheres na sociedade:

Pois, que the poderia contar, senhora, dos segredos naturais que descobri cozinhando? Ver que um ovo se frita na manteiga ou no azeite e, ao contrário, se desmancha na calda; ver que para que o açúcar se conserve fluido, basta adicionar-lhe uma pequena porção de água na qual se haja mergulhado marmelo ou outra fruta ácida; ver que a gema e a clara de um mesmo ovo são tão opostas que quando usadas com açúcar, cada uma serve por si mesma, mas não juntas. Mas não devo cansá-la com tais leviandades, que apenas menciono para dar-vos notícia completa do meu modo de ser e creio que vos fará rir; mas, senhora, que podemos saber as mulheres a não ser filosofias de cozinha? Disse bem Lupercio Leonardo: Que bem se pode filosofar e preparar a janta. E eu costumo dizer, observando essas pequenas coisas: Se Aristóteles tivesse cozinhado, muito mais teria escrito. ${ }^{6}$

\footnotetext{
5 Ainda que, certamente, tenha escolhido uma das pouquíssimas vias abertas à carreira intelectual para uma mulher do século 17. Como nota Octavio Paz, professar, fazer os votos, era uma profissão na época, particularmente para jovens sem paternidade definida e sem dote. Mesmo essa 'profissão' tinha, no entanto, distinções internas: Sor Juana professou pela primeira vez no convento das Carmelitas Descalças, em 1667, e o abandonou três meses depois.

${ }^{6}$ Respuesta a sor Filotea. In: IMBERT, E. A. e FLORIT, E. Literatura hispanoamericana. Op. cit., p.144. Muitos outros autores comentaram a relação entre
} 
A observação de Sor Juana poderia conter um segundo nível de ironia, como era comum nos seus escritos, isto é, além da apresentação irônica de si e das mulheres em geral, supostamente dedicadas apenas a coisas comezinhas, ela poderia estar referindo uma convenção comum à América hispânica e portuguesa no século XVII, a de que os conventos eram lugar de produção de uma culinária elaborada. ${ }^{7}$ Mas eram também, apesar de sua população feminina, ou talvez até por causa disso, lugar de tertúlias e "conversações sábias" - ou de filosofias de cozinha, conforme a burla de Sor Juana. Octavio Paz mostra bem como a "cela" da monja era de fato um conjunto de aposentos muito espaçosos, onde ela recebia com freqüencia as pessoas da corte para entretê-las com sua poesia e prosa - e, eventualmente, com sua culinária. ${ }^{8}$ Quando a condessa de Paredes lhe enviou uma tiara de penas de colibri, "como as dos chefes astecas", Juana

escrever e cozinhar. Roland Barthes observa: "Cadmo, que trouxe a escrita para a Grécia, havia sido cozinheiro do rei de Sidon. Seja dado esse traço mitológico como apólogo à relação que une a linguagem e a gastronomia. [..] Cortou a língua, acabou-se o gosto e a palavra." Leitura de Brillat-Savarin, em O Rumor da língua. São Paulo, Brasiliense, 1988. Bakhtin também associa a comilança "à palavra, à conversação sábia, à verdade alegre": "Em toda parte, desde a Coena Cypriani até as homilias de Zenão e as sátiras e paródias mais recentes dos séculos XV e XVI, as imagens de banquete liberam a palavra, conferem um tom livre e sem temor a toda obra". BAKHTIN, M. A cultura popular na Idade Média e no Renascimento. São Paulo, Hucitec, 1987, ênfase removida. A página de Sor Juana na internet (www.dartmouth.edu sorjuana) menciona um Libro de cocina: selección y transcripción atribuídas a Sor Juana Inês de la Cruz, Convento de San Jerônimo.

7 Paz cita um viajante do século dezessete que afirmava ser comum que os frades visitassem as monjas, passando o dia com elas "escutando sua música $e$ degustando seus doces e guloseimas". "Enquanto eles comem, as monjas os distraem com suas vozes". PAZ, O. Sor Juana Inês de la Cruz... Op. cit., p.171.

8 Sor Juana, como as outras freiras, tinha uma escrava que viveu com ela cerca de dez anos, quando foi vendida, "com um filho de peito", para sua irmã. Isto é, foi vendida quando deixou de ser senhorita? 
Trampas do traje

retribuiu com um poema - e um doce de nozes. ${ }^{9} \mathrm{E}$, quando um poeta espanhol a chamou de Fênix, respondeu, bem humorada, que sendo Fênix, "não terei de moer chocolate/nem me amolarão as visitas". ${ }^{10}$

Bom humor e ironia transparecem também nas conhecidas redondilhas em que censura os homens e defende as mulheres ${ }^{11}$ :

Hombres necios que acusáis

a la mujer sin razón, sin ver que sois la ocasión, de lo mismo que culpáis: si con ansia sin igual solicitáis su desdén, por qué queréis que obren bien si las incitáis al mal?

[..]

Qué humor puede ser más raro que el que, falto de consejo, él mismo empaña el espejo y siente que no esté claro? [..] Opinión, ninguna gana; pues la que más se recata, si no os admite, es ingrata, y si os admite, es liviana.
Homens bobos que acusais as mulheres sem razão, sem ver que são ocasião, daquilo do que as culpais: se com ânsia sem igual solicitais seu desdém, como esperais que ajam bem se as incitais ao mal?

Que alento tão raro que, por falta de conselho, empana ele o espelho, e o lamenta por ser baço?

Fama, nenhuma ganha; já que a mais recatada, se não os aceita é ingrata, e se os aceita, é leviana.

9 O romance tem o número 23 na Lírica Personal e é um primor de alusões engraçadas: afirma que o deus Apolo, que é "um deus muito humano", a trata como irmã e que, depois de saber que ela era querida na corte, pede-lhe que interceda junto à Condessa para obter favores. Apolo é também feminizado num dos versos, pois lhe teria dito: "guarda essas nozes, de quem fui Cozinheira".

10 "no he de moler chocolate,/ni me ha de moler a mi/ quien viene a visitarme." Citado por PAz, O. Sor Juana Inês de la Cruz... Op. cit., p.395.

${ }^{11}$ Obras Completas de Sor Juana Inês de la Cruz, vol. I Lírica Personal, com introdução e notas de Alfonso Méndez Plancarte. México, Fondo de Cultura Econômica [1951], 1997. Minha tradução é ligeiramente diferente da de Vera Mascarenhas de Campos em BARRETO, Teresa Cristófani. Letras sobre o espelho. São Paulo, Iluminuras, 1989. 
Mariza Corrêa

[..]

Quál mayor culpa ha tenido, en una pasión errada:

la que cae de rogada,

o el que ruega de caído?

O cuál es más de culpar,

aunque cualquiera mal haga:

lo que peca por la paga,

o el que paga por pecar?

Quem culpa maior há tido

numa paixão errada:

a que cai derrogada,

ou quem roga decaído?

A quem se deve inculpar, se ambos se vão danar: a quem peca por pagar, ou quem paga por pecar?

Sua língua afiada é legível também em alguns epigramas e sonetos satírico-burlescos. Em resposta a alguém que mencionara sua bastardia ${ }^{12}$, escreveu:

El no ser de Padre honrado

fuera defecto, a mi ver,

si como recibí el

ser de él, se lo hubiera yo dado.

Más piadosa fue tu Madre,

que hizo que a muchos

sucedas:

para que, entre tantos, puedas

tomar el que más te cuadre.
Não provir de pai honrado

creio que só seria defeito

se, como ele havia feito,

a vida, eu tivesse dado

Tua mãe, por piedade,

fazendo-te herdeiro de

tantos,

deixou-te a veleidade

de escolher entre muitos.

Os sonetos satírico-burlescos são poucos, e, comenta o organizador de suas obras completas, grosseiros, de acordo com a época. Mostram, além de sua língua afiada, uma arguta observadora dos costumes mexicanos, como este:

Aunque eres, Teresilla, tan muchacha,

le das quehacer al pobre Camacho,

porque dará tu disimulo um chacho

a aquél que se pintare más sin tacha.

\footnotetext{
${ }^{12}$ A expressão "filha da Igreja" em sua certidão de batismo será retomada com orgulho em outras ocasiões - como quando elogia a Condessa de Paredes por ser piedosa e, mesmo sendo seu filho legítimo, querer chamá-lo de filho da Igreja. Romance 24 na Lírica personal.
} 
Trampas do traje

De los empleos que tu amor despacha anda el triste cargado como um macho, $y$ tiene tan crecido el penacho que ya no puede entrar si no se agacha.

Estás a hacerle burlas ya tan ducha, y a salir de ellas bien estás tan hecha, que de lo que tu vientre desembucha sabes darle a entender, cuando sospecha, que has hecho, por hacer sua hacienda mucha, de ajena sembra, suya la cosecha.

\author{
A tradução é árdua, tento uma paráfrase ${ }^{13}$ : \\ Embora sejas tão jovem, Teresinha, \\ dás muito trabalho ao pobre do Camacho, \\ pois por sonsa lhe darás herdeiro \\ ao primeiro bonitão que te apareça. \\ Dos usos que fazes do amor \\ anda o triste carregado como um macho, \\ e já tem tão crescido o penacho, \\ que só pode entrar se se agacha. \\ Estás a troçar dele tão afeita, \\ e a te saíres bem tão acostumada, \\ que lhe dás a entender, quando suspeita, \\ que o que sair do teu ventre foi feito, \\ para aumentar em muito sua colheita, \\ com semente alheia, em terra dele.
}

\footnotetext{
${ }^{13}$ Ruedas analisou este soneto numa palestra no Instituto de Estudos da Linguagem em outubro de 2003, observando que, ao contrário do que dizem alguns de seus analistas, tais versos não seriam exemplo de um "anti-feminismo" de Sor Juana, mas o contrário. Octavio Paz corrobora essa visão. Arrolando os vários casos de mães solteiras na família de Sor Juana, diz ele que "sua sátira contra os homens e sua defesa das mulheres deixam de ser uma opinião: são uma reação moral e até física ante experiências vividas". PAZ, O. Sor Juana Inês de la Cruz... Op. cit., p.102.
} 
Podia-se ser feminista no século XVII? - pergunta retoricamente Octavio Paz, analisando essas estrofes, para mais uma vez reconduzir Sor Juana ao âmbito seguro das convenções de seu tempo. Seu livro é de fato, além de um admirável trabalho de levantamento de fontes e de uma profissão de fé de admirador da poeta, uma extensa tentativa de comprovar o convencionalismo dela. ${ }^{14}$ Deduzindo da análise da sociedade hierarquizada e estratificada da Nova Espanha na época, e de suas convenções sociais, especialmente a etiqueta da corte, um comportamento que assentia a essas convenções, Octavio Paz acaba por fazer o retrato de uma Sor Juana quase estereotipada apesar de suas vivas demonstrações do contrário. Afinal, foi por ser uma voz dissonante que a dela foi ouvida para além das fronteiras de seu país, tornando-a uma intelectual ímpar em seu tempo. ${ }^{15}$ Talvez a discussão a respeito de sua feminilidade/ masculinidade, centro do debate sobre ela desde o início de sua fama, seja o ponto crucial dessa escolha pela estereotipia e vale a pena, assim, examiná-la mais de perto.

\section{A décima musa}

Em 1946 um alemão de nome onomatopéico, Pfandl, resolveu lançar mão de seus conhecimentos psicanalíticos para analisar Sor Juana, numa obra definida por Octavio Paz como "um delírio de interpretação", e "aborrecidos repertórios dos

${ }^{14}$ Convenções poéticas e convenções cortesãs à parte - e Sor Juana parecia versada nelas - ela certamente era uma prenda da Coroa e na sua obra poética, mesmo quando se tratava de elogiar os poderosos, lê-se claramente a troca envolvida na sua relação com eles. Sobre o tema da bajulação aos poderosos no teatro religioso do início da história americana, ver KARNAL, Leandro. Teatro da fé. Representação religiosa no Brasil e no México do século XVI. São Paulo, Hucitec, 1998.

15 "Em seu século, apenas Lope de Veja, Góngora e Calderón tiveram fama tão ampla; depois, na época moderna, só Dario, Neruda e Borges." Ver também sua metáfora do pecado como desafinação. PAz, O. Sor Juana Inês de la Cruz... Op. cit., pp.414; 312. 
Trampas do traje

lugares comuns da psicanálise". ${ }^{16} \mathrm{O}$ autor analisa a obra de Sor Juana a partir de uma suposta fixação paterna, ironizada por $\mathrm{O}$. Paz, já que ela provavelmente nem conhecera o pai, e a define como intersexual.

A ambigüidade de gênero de há muito a perseguia: na carta em que praticamente rompia com seu confessor, graças à insistência dele em que abandonasse seus estudos, ela se queixava de que tivera de mudar até a forma de sua letra - muito masculina, dizia-se. Vários de seus biógrafos enfatizam a sua idéia, gorada, de vestir trajes masculinos para poder freqüentar a universidade - e sutilmente vinculam suas amizades femininas, $e$ os poemas amorosos escritos para suas amigas, à ambigüidade que Pfandl analisaria. Mas o efeito de ambigüidade mais interessante em sua história tem passado quase desapercebido, por assemelhar-se a uma trampa religiosa - trampas da fé quando parecia tratar-se, de fato, de um comentário sobre masculinidade e feminilidade na sua época.

Quando criticou o sermão do padre Vieira ${ }^{17}$, Sor Juana arriscou-se a ocupar um palco reservado não apenas a religiosos de renome, mas a religiosos homens. O bispo de Puebla, Manuel Fernandez de Santa Cruz, ao mandar publicar o texto, publicou junto uma reprimenda por ela não se dedicar mais a assuntos sacros - afirmando que, se é verdade que São Paulo disse que as

${ }^{16}$ PAz, O. Sor Juana Inês de la Cruz... Op. cit., p.95. O livro de Ludwig Pfandl foi publicado em espanhol em 1963 - Sor Juana Inês de la Cruz, la décima musa de México. Su vida, su poesia, su psique. É interessante que em sua defesa de Sor Juana contra a análise de Pfandl, $\mathrm{O}$. Paz caia na armadilha de uma metáfora sexualizada, ao compará-la com Calderón: "Temperamento especulativo, Calderón constrói torres de razões e conceitos; Sor Juana cava minas e galerias interiores." PAZ, O. Sor Juana Inês de la Cruz... Op. cit., p.94.

17 "Carta atenagórica de la madre Juana Inés de la Cruz, religiosa profesa de velo y coro en el muy religioso convento de San Jerónimo... Que imprime y dedica a la misma sor Filotea de la Cruz, su estudiosa aficionada en el convento de la Santísima Trinidad de la Puebla de los Ángeles". O folheto foi publicado em 1690 e Octavio Paz esclarece que atenagórica quer dizer digna da sabedoria de Atenas. 
mulheres não deveriam ensinar, não disse que não deveriam aprender. "Quis apenas prevenir o risco de presunção no nosso sexo, sempre propenso à vaidade".$^{18} \mathrm{O}$ bispo assinava Sor Filotea, aludindo a outros textos teológicos $e$, no pseudônimo, à conclamação a favor das letras sacras. É justamente para essa Irmã Filotea o texto em prosa mais feminista, se se pode dizê-lo sem anacronismo, de Sor Juana, que se deleita em tratar o bispo como sendo do seu sexo. Toda a peça pode ser lida em duas claves, a aparente, na qual Sor Juana se defende das críticas, $e$ uma espécie de sub-texto, na qual faz ressoar, insistentemente, um coletivo, "nós, mulheres", que sabia não adequado ao bispo, mas que parece diverti-la, apesar da seriedade da situação em que se encontrava. No final da carta, quase deixa transparecer no texto seu conhecimento do autor, fazendo uso de um jogo de palavras com o véu da religião e o véu do pseudônimo do bispo:

Se o estilo desta carta, minha venerável Senhora, não tiver sido como a vós é devido, peço perdão pela familiaridade caseira ou menos autoridade que, tratando-vos como a uma religiosa de véu, minha irmã, me fez esquecer a distância de vossa ilustríssima pessoa, pois, se a visse sem véu, tal não ocorreria; mas vós, com vossa cordura $e$ benemerência, suprireis ou corrigireis os termos; e se vos parecer incongruente o vós que utilizei, por parecer-me que para a reverência que vos devo é muito pouca reverência para a Reverência, transformai-o no que vos parecer decente ao que vós mereceis, pois eu não me atrevi a exceder os limites de vosso estilo nem a transpor a fronteira de vossa modéstia. ${ }^{19}$

\footnotetext{
${ }^{18}$ PAz, O. Sor Juana Inês de la Cruz... Op. cit., p.519.

${ }^{19}$ IMBERT, E. A. e FlORIT, E. Literatura hispano-americana. Op. cit., p.147. A tradução que faço é ligeiramente diferente da publicada em português por Teresa Cristófani Barreto em Letras sobre o espelho. São Paulo: Iluminuras, 1989.
} 
Trampas do traje

Octavio Paz mostra toda a trama política mais ampla que se pode ler a partir dessa pequena intriga colonial e não vem ao caso repetir aqui sua avaliação e, claro, comenta a defesa do "sexo fraco" feita no texto. ${ }^{20}$ Esse é apenas um dos reiterados travestismos envolvidos em toda sua trajetória, conhecidos dos personagens em privado, e utilizados, aparentemente, para satisfazer convenções públicas da época. ${ }^{21}$ Um bispo, príncipe da Igreja, não mandaria publicar (ainda que ele lhe tenha dado seu aval) uma crítica escrita por uma religiosa, sem colocar-se no seu nível - mas por que assumir uma persona feminina? ${ }^{22}$ Assim também, quem assinava a resposta à crítica de Sor Juana a Vieira, só publicada em 1727, era a monja portuguesa Irmã Margarita Inácia - mas a autoria era de seu irmão, Luiz Gonçalves Pinheiro. Isto é, que ao contrário do que pensava Pfandl, não foi Sor Juana que se masculinizou para adequar-se ao mundo das letras, mas sua entrada nele parece ter produzido um efeito de feminização em série em vários quadrantes. ${ }^{23}$ Ela própria, em seu testamento, "feminizou" seu nome, ao afirmar que no mundo era conhecida como Dona Juana Ramirez de Asbaje, quando no uso espanhol o

${ }^{20}$ Resumidamente, tratava-se de uma disputa pelo arcebispado. O arcebispo afinal nomeado era grande amigo de Vieira e Sor Juana amiga do bispo de Puebla, de quem um de seus sobrinhos foi secretário e biógrafo.

${ }^{21}$ Parece ter outro sentido o fato de a primeira edição de sua obra ter sido feita por um cavalheiro espanhol, encobrindo a verdadeira patrocinadora da publicação, a Condessa de Paredes, a quem as poesias de Inundación Castálida eram dedicadas.

${ }^{22}$ Dizia ele na apresentação do folheto - aliás, sinalizando, de passagem, que eram comuns os votos amorosos entre mulheres - que "há muito anos lhe beijou as mãos" e desde então "vive enamorado de sua alma". Citado em PAZ, O. Sor Juana Inês de la Cruz... Op. cit., p.183. (Teria ele escrito "enamorado" ou "enamorada"?)

${ }^{23} \mathrm{O}$. Paz cita um anagrama em homenagem a Sor Juana, publicado no segundo tomo de suas obras (1692), e que usa versos dela para defendê-la em seu direito a escrever poesia: Claro honor de las mujeres/y del hombre docto ultraje,/vos próbais que nos es el sexo/de la inteligencia parte. PAZ, Octavio. Sor Juana Inês de la Cruz... Op. cit., p.560. 
sobrenome de seu pai viria antes - Juana de Asbaje Ramirez. O nome do pai parece lhe ter sido devolvido por Amado Nervo em Juana de Asbaje - e assim constava de uma moeda mexicana cunhada com sua efígie em $1991 .^{24}$

Já Sor Juana afirmava em muitos textos em prosa e verso que as almas não têm sexo. $\mathrm{E}$, a um peruano que lhe aconselhava tornar-se homem, respondia com graça que em Latim uxor (mulher) só se diz para as casadas, sendo os virgens "comum de dois":

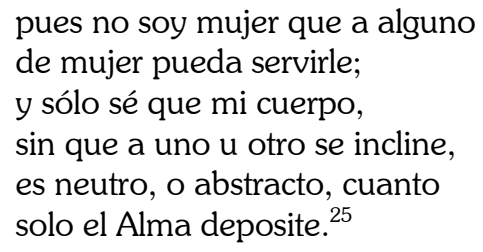

Poeta, Sor Juana amiúde invoca as musas, "as nueve Hermanas", com quem parece estar em permanente conluio: assim como ela troca doces e confidências com a Condessa, elas lhe emprestam retalhos de vestidos para cobrir seu estilo nu $e$ acorrem pressurosas quando ela as chama. ${ }^{26}$ Intelectual de seu tempo, tendo sido tão enfatizada sua afinidade com os neoplatônicos, parece justo que tenha vindo a ser conhecida como a décima musa - expressão de um epigrama de Platão dedicado a Safo.

\footnotetext{
${ }^{24}$ Ver a observação sobre seu testamento, sem a conseqüência que tiro dela, em Lírica personal, p. LVII.

${ }^{25}$ Lírica personal, romance 48.

${ }^{26}$ Ver sua evocação das nove irmãs nos romances 48 e 50. Lírica personal.
} 
Trampas do traje

\section{Uma gramática americana ${ }^{27}$}

Sabemos que a tensão entre a virgem de Guadalupe Maria, aparecida a um índio mexicano - e a Malinche - amante e tradutora de Cortés - perpassa a história cultural mexicana. ${ }^{28}$ Sabemos também que Sor Juana professou num dos conventos dedicados exclusivamente às crioulas, nativas da terra, e conhecemos suas evocações e uso da língua náhuatl (asteca) e dos ritmos e costumes de seu povo em seus poemas. ${ }^{29}$ Não sabemos se era mestiça - mas sabemos que mesclou a sua $e$ outras terras, a sua e outras tradições nos seus versos: mestiça, se não no sangue, nas idéias, como dizia Silvio Romero, referindo-se à mestiçagem brasileira. Seu traje de monja, suas líricas de adulação ao poder, seus sonetos religiosos, eram, de fato, uma trampa (trama, enredo, tramóia), a única disponível no seu tempo, para registrar essa gramática americana, de um modo um tanto enviesado, já que não foi escrava, mas mesmo assim honrou o nome da mãe.

\footnotetext{
${ }^{27}$ Ver a referência de Donna Haraway, neste número, a esta expressão da escritora americana Hortense Spillers, que comenta a crise no léxico do gênero como conseqüência da inexistência do nome do pai num continente marcado pela escravidão.

${ }^{28}$ PAz, Octavio O labirinto da solidão. Rio de Janeiro, Paz e Terra, 1984.

29 "Qué mágicas infusiones/de los índios herbolarios/de mi pátria, entre mis letras/el hechizo derramaron?" Ver, em Paz, p. 418, um poema escrito em náhuatl e p. 419, outro, inspirado na fala dos negros: "Tumba, la-la-la;tumba lale-le;/que donde ya Pilico, escrava no quede!/ Tumba, tumba, la-le-le;tumba lala-la,/que donde ya Pilico, no quede escrava!".
} 